\title{
D-Serine in Neurobiology: CNS Neurotransmission and Neuromodulation
}

\author{
Sanaa K. Bardaweel, Muhammed Alzweiri, Aman A. Ishaqat
}

\begin{abstract}
Homochirality is fundamental for life. L-Amino acids are exclusively used as substrates for the polymerization and formation of peptides and proteins in living systems. However, D- amino acids were recently detected in various living organisms, including mammals. Of these D-amino acids, D-serine has been most extensively studied. D-Serine was found to play an important role as a neurotransmitter in the human central nervous system (CNS) by binding to the N-methyl- D-aspartate receptor (NMDAr). D-Serine binds with high affinity to a co-agonist site at the NMDAr and, along with glutamate, mediates several vital physiological and pathological processes, including NMDAr transmission, synaptic plasticity and neurotoxicity. Therefore, a key role for D-serine as a determinant of NMDAr mediated neurotransmission in mammalian CNS has been suggested. In this context, we review the known functions of D-serine in human physiology, such as CNS development, and pathology, such as neuro-psychiatric and neurodegenerative diseases related to NMDAr dysfunction.
\end{abstract}

RÉSUMÉ: La D-sérine en neurobiologie : neurotransmission et neuromodulation dans le SNC. l'homochiralité est fondamentale à la vie. Chez les organismes vivants, seuls les acides aminés lévogyres sont utilisés comme substrats pour la polymérisation et la formation de peptides et de protéines. Cependant, des acides aminés dextrogyres ont été détectés récemment dans différents organismes vivants dont des mammifères. Parmi ces acides Daminés, la D-sérine a été la plus étudiés. La D-sérine jouerait un rôle important comme neurotransmetteur dans le système nerveux central (SNC) chez l'humain en se liant au récepteur de la N-méthyl-D-aspartate (NMDAr). La D-sérine se lie avec une haute affinité à un site co-agoniste du NMDAr et, avec le glutamate, sert de médiateur dans plusieurs processus physiologiques et pathologiques vitaux dont la transmission NMDAr, la plasticité synaptique et la neurotoxicité. C'est pourquoi on pense que la D-sérine jouerait un rôle clé comme déterminant de la neurotransmission médiée par NMDAr dans le SNC des mammifères. Dans ce contexte, nous revoyons les fonctions connues de la D-sérine en physiologie humaine, telles le développement du SNC et certaines pathologies comme les maladies neuropsychiatriques et neurodégénératives en lien avec une dysfonction de NMDAr.

Can J Neurol Sci. 2014; 41: 164-176

\section{Introduction}

Amino acids are among the most significant molecules in nature and exist in an L- and a D-form. The chemical and physical properties of L- and D-amino acids are enormously similar except for their optical characteristics ${ }^{1}$. During the emergence of life, only the L-amino acids were selected for the formation of polypeptides and proteins. It is still a mystery why the L-isomer of amino acids was chosen in preference to the Disomer during chemical evolution. However, polymers comprising many diastereoisomers of amino acids do not fold appropriately ${ }^{2,3}$. Nonetheless, the most broadly accepted theory for proteins homochirality supports the idea that primitive life acquired proteins by an as yet unknown mechanism ${ }^{2,3}$.

Only a few decades ago, it was largely believed that free Damino acids are not present in mammals and that D-amino acids were restricted to some bacteria and insects. Often, D-amino acids were called "unnatural" amino acids and they were considered to be the by-products of micro-organisms metabolism. In 1950, free D-alanine was isolated from the blood of the milkweed bug ${ }^{4}$. Several other reports demonstrated the occurrence of D-alanine, D-phenylalanine, D-glutamate, Dornithine, D-serine, D-asparagine, D-methionine, and Dcysteine in animal proteins ${ }^{5-8}$. Nevertheless, in the last decade, evidence has begun to accumulate that D-amino acids occur in mammals at significant levels.

The first report to show the presence of substantial quantities of free D-amino acids in mammalian tissues was by Dunlop et al 1986 where, surprisingly, a large amount of D-aspartic acid (DAsp) in the cerebrum of a newborn rat and in the pituitary gland of an adult rat was reported ${ }^{9}$. A second D-amino acid, D-serine, was then identified in considerable amounts in the brains of rodents and $\operatorname{man}^{10,11}$. Successive studies verified that some Damino acids exist in the mammalian central nervous system (CNS) and peripheral tissues in, unpredictably, high concentrations that may exceed the level of L-amino acids occurrence $^{11}$. The unanticipated detection of large amounts of endogenous D-serine in the brain, by Hashimoto et al, initiated a series of studies from several laboratories that investigated the physiological role of endogenous D-serine. Recently,

From the Department of Pharmaceutical Sciences, Faculty of Pharmacy, the University of Jordan, Amman, Jordan.

Received May 22, 2013. Final Revisions Submitted October 2, 2013. Correspondence to: Sanaa K. Bardaweel, Department of Pharmaceutical Sciences, Faculty of Pharmacy, the University of Jordan, Queen Rania Street, Amman 11942, Jordan. Email: S.bardaweel@ju.edu.jo. 
endogenous D-serine has been associated with several physiological and pathological N-methyl-D-aspartate receptor (NMDAr)-reliant processes, including NMDAr transmission and synaptic plasticity ${ }^{12-18}$, cell migration ${ }^{19}$ and neurotoxicity ${ }^{20-25}$.

In this context, we review the known functions of free Dserine in the mammalian CNS in health and disease. As evidence is rising for a role of D-serine in a number of important physiological and pathological processes in human CNS, increased comprehension of these processes will add to our understanding of human CNS (patho-)physiology, with the eventual purpose to generate novel therapeutic approaches for a variety of devastating and poorly treatable CNS conditions.

\section{D-Serine Localization}

The distribution of D-serine is parallel to the distribution of NMDA type glutamate receptors ${ }^{11}$. D-Serine has been detected at relatively high levels in certain areas in the adult brain with particularly high levels of NMDArs, including cerebral cortex, hippocampus, thalamus, hypothalamus, amygdala, and retina. Nonetheless, brain regions, such as the hindbrain, pons, and medulla have nearly imperceptible levels of D-serine ${ }^{26}$. Significantly, it has been demonstrated that D-serine is localized principally within glial cells ${ }^{14,16,19,26,27}$. In the retina, Stevens et $a l^{15}$ reported the occurrence of D-serine in astrocytes and Müller glia cells. Recently, several studies suggest that the synthesis, storage, and release of D-serine may not be limited exclusively to astrocytes, but rather may involve specific functions for certain cells ${ }^{28}$.

\section{D-Serine Biosynthesis and Metabolism}

In humans, there are four sources from which D-amino acids can be obtained; ingestion of food, liberation from gastrointestinal bacteria, release from metabolically stable proteins, and through biosynthesis from L-amino acids (Figure 1). Endogenous L-serine is directly converted into D-serine by the enzymatic activity of serine racemase (SR), a brain-enriched enzyme ${ }^{29-31}$. Serine racemase needs cofactors pyridoxal 5'phosphate, magnesium, and adenosine triphosphate (ATP) for its catalysis $^{26-28}$. The enzyme is distinctive among the pyridoxal 5'phosphate-dependent enzymes as it requires both, divalent cations and the Mg.ATP complex for its activity ${ }^{29,32-34}$.

The regional distribution of SR matches that of endogenous D-serine, indicating a physiological role in D-serine synthesis ${ }^{30}$. In the brain, SR localizes to protoplasmic astrocytes in a very analogous pattern to D-serine localization ${ }^{30,31}$. Evidence supporting the synthesis of D-serine by SR in the glia was associated with the strong spatiotemporal relationship between $\mathrm{D}$-serine and $\mathrm{SR}^{35}$ and by the reduction of $\mathrm{D}$-serine concentrations in astrocytes after pharmacological inhibition of $\mathrm{SR}^{30}$. Additionally, heterologous overexpression of SR in living cells resulted in D-serine synthesis, providing further evidence for the role of SR in D-serine production ${ }^{36}$. Preliminary studies reveal that SR knockout mice exhibit an $80-90 \%$ reduction in brain D-serine levels, verifying the role of SR as the biosynthetic enzyme for D-serine ${ }^{37-40}$.

Recently, Benneyworth et al used recombinant DNA techniques to study the effect of cell type selective suppression of SR expression in astrocytes (aSRCKO) and in forebrain glutamatergic neurons (nSRCKO). Unexpectedly, although a significant reduction of SR protein was observed in neuronal SR null mutant mice, D-serine levels were only minimally reduced suggesting that neurons are not the only source of brain D-serine. Additionally, liver expression of SR was increased by $35 \%$ in the neuronal SR null mutant, signifying a role for peripheral SR in the maintenance of brain D-serine ${ }^{41}$.

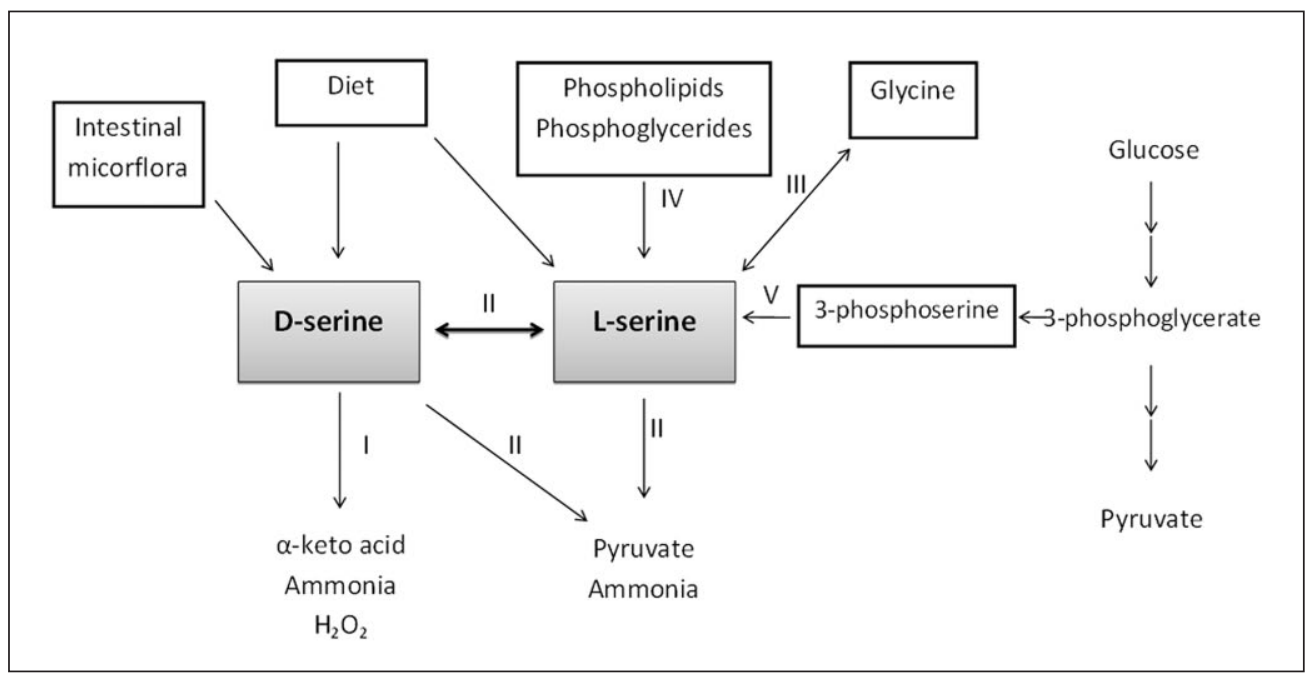

Figure 1: Pathways of D-serine biosynthesis and catabolism. I: D-amino acid oxidase; II: Serine racemase; III, serine hydroxymethyltransferase; IV: synthesis of phospholipids and phosphoglycerides from cytidine diphosphodiacylglycerol and palmitoyl-coenzyme $A ; V:$ 3-phosphoserine phosphatase and 3phosphoglycerate dehydrogenase. 
Another metabolic function that is connected to SR, in addition to its racemase activity, is the L-serine and D-serine conversion into pyruvate and ammonia via $\alpha, \beta$-elimination of water $^{29,42}$. Pyruvate formed by SR appears to provide the energy requirements of the astrocytes ${ }^{42}$. This reaction further implies that SR is not only involved in D-serine synthesis, but also in Dserine metabolism as a mechanism to regulate the intracellular occurrence of D-serine ${ }^{42}$.

Interestingly, although neurons have high levels of SR, the occurrence of its substrate L-serine in neurons is negligible. It has been shown that the biosynthesis of L-serine from glucose is localized almost exclusively in astrocytes ${ }^{43,44}$ but not neurons, necessitating the transport of astrocytic L-serine to neurons where it can then be converted to D-serine. After its synthesis, Dserine in neurons is transported to astrocytes where it is stored and released ${ }^{45}$. Relative to neurons, the lower level of SR in astrocytes, constitutes a suitably protected D-serine storage compartment, confiscating it from degradation by neuronal SR. Furthermore, mammalian D-amino acids can be metabolized by the peroxisomal flavoprotein D-amino acid oxidase $(\mathrm{DAO})^{46}$, with the simultaneous reduction of the co-factor flavin adenine dinucleotide $(\mathrm{FAD})^{47}$. The substrate specificity of DAO is selectively restricted to the metabolism of neutral D-amino acids, displaying the highest affinity for D-serine, D-alanine, Dproline, D-leucine, and D-methionine in vivo ${ }^{48-50}$. Interestingly, the metabolism of D-serine by DAO was first proposed based on the reciprocal pattern of D-serine levels and the noticeable regional and developmental variation in DAO levels ${ }^{26,35}$. As for its localization, DAO is highly expressed in the kidneys, followed by the liver, and the CNS, where DAO is found in astrocytes of the hindbrain and cerebellum ${ }^{51}$, with a presumed preferential localization to type I astrocytes ${ }^{52}$.

\section{Biological Function of D-Serine}

\subsection{NMDAr Neurotransmission}

The evident association between the anatomical distribution of D-serine and the localization of the NMDAr suggests a functional relationship. NMDArs are largely distributed throughout the CNS and play a major role in glutamatergic synaptic transmission ${ }^{53}$. NMDArs are tetrameric ionotropic receptor channels that are major excitatory receptors in the brain; they play various roles in different physiological processes, such as NMDA transmission, synaptic plasticity, and development ${ }^{53}$.

Multiple subtypes of NMDAr exist; frequently encompassing an NR1 subunit combined with at least one of four NR2 (A-D) subunits. A third subunit, NR3, can co-assemble with NR1/NR2 complexes. The biophysical and pharmacological properties of NMDArs vary according to their subunit composition ${ }^{54}$. One of the distinctive attributes of NMDArs is that they are only stimulated upon simultaneous binding of more than one agonist. Glutamate is a known NMDAr agonist, but alone it cannot stimulate the receptor; it needs the binding of co-agonist at the NR1 subunit of NMDAr in order to exert its function ${ }^{55}$.

Glycine was considered, for long time, as an endogenous coagonist that binds to NR1 subunit of NMDAr; thus the NR1 site was labeled as the 'glycine site'. The co-agonist binding on NR1 subunit is not only crucial for NMDAr activation, but also exerts a neuromodulatory role by increasing the affinity of the NMDAr for glutamate ${ }^{56}$, decreasing its desensitization ${ }^{57}$, and promoting
NMDAr turnover by internalization ${ }^{58}$. Recently, the affinity of NR1 subunit for D-serine has been recognized ${ }^{14}$. It has been found that D-serine binds to the co-agonist site of NMDAr with an affinity that is three times higher than that of glycine ${ }^{14}$. The stronger binding affinity of D-serine to the co-agonist site can be explained by the displacement of a water molecule and the formation of additional three hydrogen bonds with the binding pocket $^{59}$. On the other hand, the unique selectivity of D-serine has an evident structural explanation as the hydroxyl group of Lserine interacts unfavorably in the binding pocket ${ }^{59}$.

Functional evidence for the contribution of endogenous Dserine to physiological NMDAr co-activation was reported in a pioneer study by Mothet et al. In this study, addition of DAO, an enzyme that selectively degrades $\mathrm{D}$-amino acids but not L-amino acids, to neural cell cultures resulted in depletion of endogenous D-serine and eventually noticeable reduction in NMDAr activity $^{14}$. This effect was fully reversed by the application of exogenous D-serine ${ }^{14}$. Subsequent studies demonstrated that endogenous D-serine is required for NMDAr mediated lightevoked responses in the vertebrate retina ${ }^{12,15}$.

NMDArs play a major role in excitatory transmission and synaptic plasticity, such as long-term potentiation (LTP $)^{60}$. DSerine contribution to activity-induced synaptic plasticity was further confirmed when Yang et al compared the ability to evoke LTP in cultured neurons between cells grown in direct contact with astrocytes and those grown without direct contact. Surprisingly, neurons that were not in direct contact with astrocytes failed to induce LTP. When the cells were supplemented with an exogenous source of D-serine, LTP was successfully induced ${ }^{17}$. Similarly, the contribution of D-serine to activity-induced synaptic plasticity in other brain areas, such as the hypothalamus, retina, and prefrontal cortex has been confirmed $^{16,61-63}$.

Interestingly, it has been shown that different physiological functions are exhibited by NMDAr depending on its location. Synaptic NMDArs are well known for mediating synaptic LTP whereas extrasynaptic NMDArs have been associated with the pathogenesis of certain neurodegenerative diseases such as Alzheimer's disease ${ }^{64}$. Remarkably, D-serine demonstrated a preferential effect on synaptic NMDArs whereas glycine preferentially affects the extrasynaptic receptors ${ }^{65}$. When Dserine was degraded using DAO, functions that are mediated by synaptica NMDAr, including LTP, were diminished. On the contrary, treatment with glycine oxidase, an enzyme that specifically degrades glycine, had no effect on synaptic excitatory functions ${ }^{65}$.

In hippocampal organotypic slice cultures, although extracellular glycine was 10-fold higher than D-serine, the removal of endogenous $\mathrm{D}$-serine completely blocked the NMDAr-elicited neurotoxicity ${ }^{24}$. Glycine alone failed to promote NMDAr neurotoxicity. In the absence of D-serine, the amount of glycine needed to produce maximal NMDAr neurotoxicity was two orders of magnitude higher than its dissociation constant from purified NMDArs ${ }^{24}$. Similarly, in hypoglossal neurons, D-serine was approximately two orders of magnitude more effective than glycine in stimulating NMDAr responses ${ }^{66,67}$. Additionally, as opposed to endogenous glycine degradation by a glycine oxidase enzyme, electrophysiological studies performed in the supraoptic nucleus of the hypothalamus 


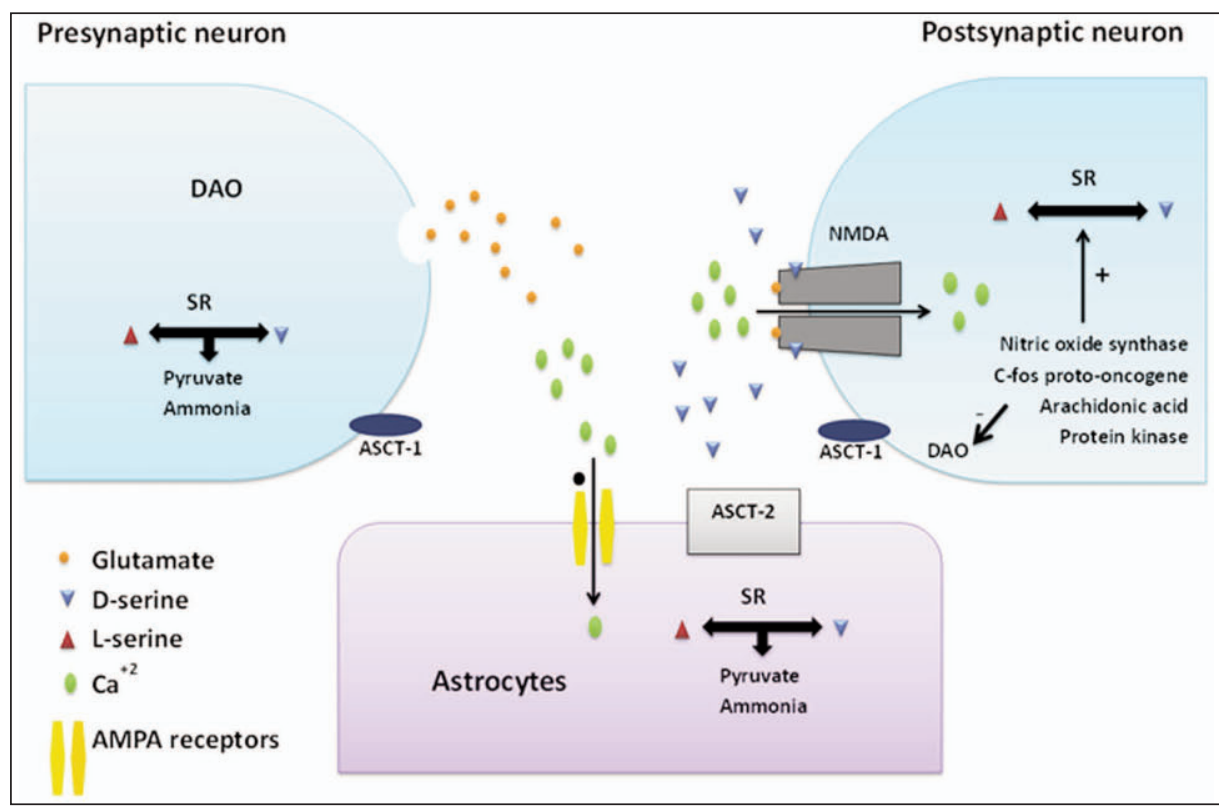

Figure 2: Possible mechanisms for regulating D-serine concentrations. Regulation of synaptic Dserine concentrations has not been fully elucidated. Presumably, ASCT2 transporters with low affinity and Asc-1 transporters with higher affinity are involved in neuronal (Asc-1) and glial (ASCT2) D-serine uptake. After uptake, peroxisomal and non peroxisomal DAO might mediate Dserine degradation. Alternatively, SR might regulate D-serine concentrations in both astrocytes and neurons by enabling $D$-serine synthesis from $L$-serine.

verified that endogenous D-serine degradation by recombinant DAO blocked NMDAr responses in hypothalamic slices ${ }^{16}$.

The difference in the functional efficiencies between D-serine and glycine, despite their affinities to NMDArs, may be attributed to the availability of the two co-agonists at synaptic or extra-synaptic sites. The synaptic glycine levels are tightly regulated via a high affinity transport system (GlyT1) that restricts glycine availability to NMDAr sites ${ }^{67,68}$. The presence of such an effective transporter of glycine keeps the glycine binding site unsaturated ${ }^{68}$. Hence, inhibition of the GlyT1 transporter potentiates NMDAr responses ${ }^{24}$ and induces NMDAr neurotoxicity in the absences of endogenous D-serine ${ }^{24}$. In addition, the glycine cleavage system (GCS) may also contribute to maintaining low glycine abundance near NMDArs. It has been found that, in astrocytes, the GCS effectively breaks down glycine and, consequently, generates the cytosol/extracellular concentration gradient, which facilitates glycine transfer from the synaptic space into astrocytes ${ }^{69-71}$

The molecular mechanisms of D-serine transport and the factors controlling its synaptic concentration are more complicated and necessitate further elucidation (Figure 2). Quite the opposite of glycine, D-serine is considered as a poorly transported amino acid. Specific D-serine transporters have not been identified yet. Nevertheless, $\mathrm{Na}^{+}$-dependent ${ }^{72}$ or $\mathrm{Na}^{+}$independent amino acid transporters ${ }^{73-76}$ are proposed to take part in D-serine transport, with the $\mathrm{Na}^{+}$-independent alanineserine-cysteine transporter 1 (ASCT1) being the most probable candidate. In contrast, neutral amino acid transporters exhibit low to moderate affinity for $\mathrm{D}$-serine $\mathrm{e}^{72,75,77}$. Interestingly,
ASCT1 transports D-serine with high affinity and shows high levels of abundance in neurons throughout the brain ${ }^{73,74,78,79}$. Evidence from gene knockout studies demonstrates that ASCT1 is the primary transporter mediating D-serine re-uptake in neurons ${ }^{78}$, while ASCT2 might be the main transporter involved in removal of synaptic D-serine into glia ${ }^{72,79}$.

While the GCS degrades glycine efficiently, thereby limiting the accessibility of glycine to NMDArs ${ }^{69-71}$, the role of DAO remains controversial in regulating D-serine concentrations near NMDArs. Despite the fact that D-serine and NMDArs are predominantly present in the forebrain, previous studies failed to detect DAO activity in forebrain ${ }^{80}$ suggesting other pathways of D-serine removal. Additionally, serine racemase (SR) largely contributes to regulation of the extracellular level of Dserine $^{42,81}$. When the synaptic D-serine concentrations are elevated, SR plays a role in the clearance of D-serine through degradation into pyruvate or conversion into L-serine. The relative importance of the enzymatic reactions and transporters in regulating the synaptic levels of D-serine has yet to be determined.

Compared to the high affinity, yet tightly regulated glycine transport systems, which keep glycine concentrations near NMDArs sufficiently low, stringent regulation of D-serine concentration appears to principally modulate the excitability of neurons via harmonizing the sensitivity of NMDArs under physiological conditions ${ }^{15}$. Requiring a second agonist, in addition to glutamate, for NMDArs stimulation might provide a protection mechanism against the neurotoxicity associated with excess glutamatergic stimulation ${ }^{82}$. 


\subsection{CNS Development}

The noticeably elevated D-serine concentrations in human and rodent $\mathrm{CNS}^{11,26,83}$ during the intense stage of embryonic and early postnatal CNS development provided the first evidence for a specific role for D-serine in CNS development. Supportive to this role, elevated D-serine concentrations coincide with transient expression ${ }^{84-87}$ and increased activity ${ }^{88-90}$ of NMDArs. Likewise, Fuchs et al reported the presence of high D-serine concentrations in human cerebrospinal fluid (CSF) during the early postnatal period ${ }^{91}$. Moreover, excessive levels of D-serine have been detected in the cerebellum of neonatal rats, decreasing to very low levels in the third week of life as a result of the emergence of $\mathrm{DAO}^{26,80}$. This temporary abundance of D-serine in the cerebellum corresponds with postnatal cerebellar development, in which granule cells migrate from the external to the internal granule cell layer in an NMDAr-dependent manner ${ }^{92}$. Moreover, it has been shown that D-serine appears to be engaged in neuronal migration. DAO catalyzed degradation of D-serine and selective inhibition of SR in eight day-old mouse cerebellar slices considerably suppressed granule cell migration, while D-serine appears to activate the migration ${ }^{19}$ through NMDAr activation ${ }^{92}$. Supportive evidence for the D-serine role in migration is provided by the definite mass spectrometric identification of SR in the perireticular nucleus, a short-lived structure of the developing brain in humans proposed to be largely involved in neuronal migration ${ }^{93}$.

Furthermore, D-serine has been found to play a role in synaptogenesis. Partial deletion of NR1 subunits of NMDArs in organotypic hippocampal cells intensely enhanced numbers of functional synapses between neurons. This effect was vanquished by the reintroduction of NMDArs ${ }^{94}$. Based on the activating role of $\mathrm{D}$-serine on NMDArs, it was proposed that endogenous D-serine prevents premature synaptic maturation and controls the induction of functional synapses for the activitydependent wiring of neuronal circuitry ${ }^{94,95}$.

\subsection{Learning and Memory}

Long-term potentiation (LTP) of synaptic transmission in the hippocampus is broadly considered as one of the key cellular mechanisms underlying learning and memory in vertebrates ${ }^{96}$. It refers to an augmentation in signal transmission between neurons upon synchronic stimulation and is one of the fundamental processes of synaptic plasticity. D-Serine released from astrocytes and NMDAr activation both appear to play a role in LTP induction ${ }^{17}$. On the other hand, NMDAr antagonists and enzymatic D-serine degradation suppressed LTP induction ${ }^{17}$. Further support provided from studies on SR knockout mice, where it had been shown that depletion of D-serine concentrations was directly related to an impaired NMDAr transmission and attenuated $\mathrm{LTP}^{97}$. On the contrary, DAO knockout mice display high extracellular D-serine concentrations, improved NMDAr function, and enhanced hippocampal LTP ${ }^{98,99}$

Studies assessing learning and memory decline occurring with aging revealed that SR expression, D-serine concentrations, NMDAr-mediated synaptic potentials, and LTP were all drastically decreased in CA1 hippocampal slices from aged rats when compared with young rats, and were all restored by exogenous D-serine ${ }^{13,66,100}$. Similarly, hippocampal slices from a senescence-accelerated mouse model exhibited substantial and amplified LTP suppression with age, when compared to normal mice, which was overcome by D-serine supplementation ${ }^{18}$.

Collectively, these results strongly demonstrate the significance of D-serine for NMDAr activation and subsequent LTP induction that underlies learning and memory.

\section{D-Serine in CNS Diseases}

As it is involved in NMDAr neurotransmission in the brain, NMDAr-dependent plasticity, and developmental processes, it is not astonishing that dysregulation of D-serine signaling might also be involved in several pathologies, including neuropsychiatric and neurodegenerative diseases related to NMDAr dysfunction. Intense stimulation of NMDArs has been associated with considerable number of acute and chronic neurodegenerative conditions, including stroke, epilepsy, polyneuropathies, chronic pain, amyotrophic lateral sclerosis (ALS), Parkinson's disease (PD), Alzheimer's disease (AD), and Huntington's disease (HD) ${ }^{53}$.

\subsection{Excitotoxicity}

Excitotoxicity refers mainly to excessive NMDAr activation, which leads to subsequent vast calcium influx in the cell ${ }^{53}$. Cell death upon hypoxia/ischemia and neurodegenerative conditions is directly related to excitotoxicity ${ }^{101}$. Several studies support the role of D-serine in excitotoxicity, as it is a potent endogenous coagonist at the NMDAr. Removal of endogenous D-serine with $\mathrm{DAO}^{20}$ or D-serine deaminase ${ }^{24}$, a D-serine degrading enzyme, nearly eradicated NMDA-elicited neurotoxicity in rat cerebrocortical and organotypic hippocampal slices. Furthermore, SR knockout mice, displaying a $90 \%$ reduction in extracellular D-serine concentrations, demonstrated reduced neurotoxicity induced by NMDA injections in their forebrains ${ }^{102}$.

\subsection{Amyotrophic Lateral Sclerosis (ALS)}

Amyotrophic lateral sclerosis (ALS) is the most common adult onset neuromuscular disease with a life-time risk of 1 in $500^{103}$. Progressive muscle weakness, atrophy, and paralysis leading to severe disability are the major consequences of the disease. The primary cause for the motoneuron failure is thought to be excitotoxicity ${ }^{104}$.

Elevated glutamate levels have been detected in the cerebrospinal fluid of ALS patients ${ }^{105}$. In addition, D-serine, was detected at elevated levels, both, in spinal cord from sporadic cases of ALS and in an animal model of $\mathrm{ALS}^{23}$. Interestingly, a mutation in DAO, which is highly abundant in spinal cord motor neurons and brain stem motor nuclei, was found to have association with familial ALS ${ }^{106}$. Neuronal cell lines expressing the mutant DAO showed decreased viability and increased ubiquitinated aggregates compared with cells expressing the wild-type protein ${ }^{106}$.

\subsection{Alzheimer's Disease}

Alzheimer's disease (AD) is a progressive neurodegenerative disorder involving a reduction of synaptic density in specific brain regions, leading to a global impairment of higher mental function ${ }^{107}$. Evidence has begun to accumulate suggesting a role of NMDAr in the pathophysiology of $\mathrm{AD}^{107-110}$. 
The neurochemical basis of AD remains largely unclear. Previously, it has been shown that NMDArs are selectively and differentially diminished in specific regions of the brain in patients with $\mathrm{AD}^{111-113}$, suggesting that $\mathrm{AD}$ might be associated with a loss of NMDAr activity. Nevertheless, recently, an antagonist of NMDAr, memantine, was found to reduce clinical deterioration in patients with moderate-to-severe $\mathrm{AD}^{114}$.

The foremost constituent of amyloid plaques found in the brains of Alzheimer's patients is amyloid beta-peptide, which appears to be the most widely accepted pathological factor for Azheimer's disease. Calcium-mediated neurotoxicity caused by amyloid beta-peptide was shown to be mediated by the NMDAr ${ }^{115}$. Amyloid beta and amyloid precursor protein were both found to raise D-serine and glutamate concentrations, as well as SR transcription in cultured microglia and hippocampal neurons ${ }^{25,116,117}$. In vivo, amyloid beta-peptide neurotoxicity was attenuated in SR knockout mice, which also displayed $90 \%$ decreased brain D-serine content ${ }^{102}$.

Free D-serine levels in the frontal cortex of $\mathrm{AD}$ patients were equivalent to those in the normal brain ${ }^{118}$. On the contrary, free $\mathrm{D}$-serine levels in the ventricular cerebrospinal fluid (CSF) of AD patients were significantly higher than in normal controls ${ }^{119}$. Interestingly, D-cycloserine, a partial agonist of the glycine site of the NMDAr, was shown to enhance the performance of memory-related tasks in patients with $\mathrm{AD}^{120,121}$. It, also, has been reported that administration of D-serine immediately after bilateral lesion of perirhinal cortex produced full restoration of retrograde memory in rats, measured by a visual brightness discrimination task ${ }^{122}$.

\subsection{Epilepsy}

Epilepsy is a momentous neurological disorder distinguished by neuronal loss and spontaneous recurrent seizures. Although involvement of the NMDAr has been proposed in the pathogenesis and progression of epilepsy, the exact neurochemical basis is still to be determined. Stimulation of NMDArs by D-serine was suggested to induce seizures ${ }^{123}$, which were suppressed by NMDAr antagonists ${ }^{124,125}$. Additionally, upregulation of $\mathrm{D}$-serine was shown to provoke GABAergic neuronal degeneration through excitotoxic mechanisms, suggesting a role of D-serine in the early pathogenesis and recurrent seizures of chronic epilepsy ${ }^{126}$. On the other hand, patients exhibiting undetectable CSF D-serine concentrations were found to experience severe epilepsy that could be treated effectively by L-serine, which reinstates CSF D-serine concentrations $^{91}$. Thus, D-serine deficiency might also trigger seizures. Actually, D-serine has been shown to potentiate anticonvulsant drug therapy ${ }^{118}$ and increase the threshold for induction of seizures ${ }^{119}$.

Status epilepticus (SE) is a medical crisis that is defined as continuous seizure activity involving prolonged and sever hypoxia which may cause a sustained encephalopathy ${ }^{127}$. Recently, the relationship between spatiotemporally specific glial responses and the D-serine/ SR system in mesial temporal structures following SE was investigated ${ }^{128}$. After SE, D-serine and SR immunoreactivities were increased in astrocytes. In addition, phosphorylated NMDAr subunit 1 (pNR1-Ser896) immunoreactivity in the hippocampus was augmented compared with controls. The direct correlation between the increased levels of D-serine and the augmented phosphorylation of NMDAr subunit 1 suggests that D-serine and SR in astrocytes may participate in neuronal hyperexcitability via a cooperative activation of NMDA receptors $^{128}$.

\subsection{Bipolar Disorder}

Bipolar disorder (BD) is a serious and debilitating psychiatric condition. It is characterized by cyclic episodes of depression and mania, combined with episodes of recovery ${ }^{129,130}$. Significant associations between specific G72 markers and haplotypes and bipolar disorder were found ${ }^{131-137}$. However, studies to identify polymorphisms in candidate genes involved in D-serine regulation, such as the genes encoding for vesicleassociated membrane proteins 2 and 3, failed to show any correlation with bipolar disorder ${ }^{138}$. Nonetheless, glutamate levels were elevated in frontal cortex from patients with bipolar disorder when compared with controls and a positive correlation was observed between D-serine and glutamate ${ }^{139}$, suggesting a role for D-serine and glutamate in the pathophysiology of bipolar disorder.

\subsection{Perinatal Asphyxia}

Perinatal asphyxia is the consequence of hypoxic/ischemic pathology and occurs due to impaired blood supply between mother and fetus, leading to inadequate supply of oxygen and glucose to the fetal organs, most importantly the brain. In the long-term consequences of the disease, cerebral palsy, mental retardation, visual and acoustic impairment, and epilepsy might occur $^{140,141}$. It has been strongly suggested that excessive excitation of the NMDAr plays a vital role in the pathogenesis of hypoxic-ischemic damage, especially in the developing brain ${ }^{101,142}$. Despite the strong hypothesis, most research has focused on glutamate and its relevance to perinatal asphyxia. The contribution of D-serine to the pathogenesis remains largely elusive. However, the role of D-serine was suggested based on the reduction of cell death after addition of DAO to rat cerebrocortical slices exposed to oxygen-glucose deprivation (OGD), which was reversed by addition of D-serine ${ }^{20}$. Similarly, SR knockout mice, displaying 90\% reduced D-serine concentrations, exhibited decreased neurotoxicity and dramatically diminished infarct volume after middle cerebral artery occlusion $^{143}$.

\subsection{Schizophrenia}

Schizophrenia is a serious mental illness affecting approximately $1 \%$ of the population worldwide and it is considered as one of the leading causes of chronic disability ${ }^{144,145}$. Tremendous effort has been made to reveal the neurobiological basis of schizophrenia. Recent evidence suggests that schizophrenia pathophysiology involves widespread perturbations in a number of closely interacting neurotransmitter systems in cortical and subcortical structures $^{146}$.

Dopamine has been linked to schizophrenia, on the basis that dopamine-releasing stimulants, such as amphetamine, can stimulate psychotic symptoms ${ }^{147}$, and antipsychotic drugs decrease psychotic symptoms by the antagonism of dopamine D2 receptors ${ }^{148,149}$. Patients with schizophrenia may experience 
positive symptoms (delusions and hallucinations), negative symptoms (apathy, social isolation), and cognitive symptoms (problems in memory, and mental abilities) ${ }^{144}$. Drugs that work as dopamine antagonists, such as typical antipsychotics, were the mainstay of schizophrenia treatment for a long time. However, they addressed the positive symptoms only and failed to prevent the negative and cognitive symptoms ${ }^{150}$. The restricted capacity of D2 antagonists to improve negative and cognitive impairments suggests the involvement of other neurotransmitter systems, such as glutamate and $\gamma$-aminobutyric acid (GABA) ${ }^{151}$.

NMDAr hypofunction has been proposed to play a role in the pathophysiology of schizophrenia based on the observation that noncompetitive NMDAr antagonists, such as phencyclidine or ketamine, can trigger transient schizophrenia-like symptoms in healthy individuals ${ }^{152,153}$ and can aggravate symptoms in patients ${ }^{154-160}$. Diminished D-serine concentrations ${ }^{161}$ and reduced D-serine to total serine ratio in $\mathrm{CSF}^{161,162}$ and serum ${ }^{163}$ of patients with schizophrenia lead to a hypothesis suggesting the contribution of D-serine to NMDAr hypofunction. In accordance with the previous observations, suggesting that reduced levels of D-serine and hypofunction of NMDA receptors were associated with schizophrenia, Calcia et al ${ }^{164}$ recently reported that plasma levels of D-serine and the ratio of plasma Dserine to total serine were significantly lower in a sample of 84 Brazilian individuals with schizophrenia. Nonetheless, normal D-serine concentrations were detected in the parietal or prefrontal cortex from patients with schizophrenia ${ }^{161,165}$.

The observations that DAO levels and activity are elevated in schizophrenia patients ${ }^{166,167}$ provided a foundation for the diminished D-serine level hypothesis. Numerous meta-analyses of genetic association studies in schizophrenia convey some evidence for a connection between the DAO gene and schizophrenia ${ }^{168-170}$. Amplified DAO expression ${ }^{171-173}$ and activity $^{171}$ in cerebellum, parietal cortex ${ }^{166}$ and hippocampus ${ }^{167}$ of patients with schizophrenia, when compared with controls, support the association between DAO and schizophrenia. Another gene product, which is directly related to the metabolism of D-serine, has been proposed to have an association with schizophrenia. Single-nucleotide polymorphisms in $\mathrm{SR}^{174}$ and SR genetic variants in humans showed an association with schizophrenia ${ }^{175}$. Nonetheless, SR activity has not been assessed in schizophrenia as of yet. Upon comparing schizophrenic patients with controls, no change in SR expression was observed in the parietal cortex ${ }^{172}$ or in the cerebellum and prefrontal cortex ${ }^{173}$. SR knockout mice, displaying $90 \%$ D-serine reduction, demonstrated moderate behavioral abnormalities, including hyperactivity, impaired spatial memory and increased anxiety, which are all relevant to schizophrenia ${ }^{97}$.

Recently, genetic association studies have linked numerous mutations in human D-serine metabolic enzymes to schizophrenia and thus conclusive evidence for a role of Dserine in the pathology of schizophrenia has been provided. Single-nucleotide polymorphism (SNP) variants of $\mathrm{SR}^{174}$, $\mathrm{DAO}^{176,177}$, and the DAO interacting protein $\mathrm{G} 72^{133,135,178-184}$ were all identified as risk factors for schizophrenia. Notably, G72 transgenic mice exhibit a sensorimotor gating insufficiency that can be reversed by haloperidol, an antipsychotic drug, suggesting that G72 gene could be a convincing schizophrenia candidate gene ${ }^{185}$.
The efficacy of several combinations of D-serine with antipsychotic therapies were shown to be more successful in the alleviation of various symptoms of schizophrenia than antipsychotics alone ${ }^{150,186,187}$. Recently, the feasibility, safety, tolerability, and efficacy of a combination of D-serine and computerized cognitive retraining (CRT) for the treatment of cognitive deficits of schizophrenia, has been evaluated ${ }^{188}$. While D-serine and CRT did not show any significant effect on the Global Cognitive Index, both interventions showed discrepant effects on individual test performance. These findings support further investigation into the role of D-serine in schizophrenia.

\subsection{Depression}

Depression is a heterogeneous disease with a highly variable course and no established mechanism. The diseases is characterized by distinct mood disturbances that involve sadness and irritability along with various psychophysiological changes ${ }^{189}$. Although depression is treatable and many antidepressant drugs are available, the treatment regimens have many limitations and are still insufficient for many patients.

Several different models have been suggested for mechanisms underlying depression, including monoamine deficiency $^{190}$, reduced GABAergic neurotransmission ${ }^{191}$, abnormal circadian rhythms ${ }^{192}$, and altered glutamatergic neurotransmission ${ }^{191}$. Furthermore, research revealed that structural alterations at the molecular and cellular levels of neurons in the CNS are associated with depression ${ }^{193}$. Although the monoamine deficiency hypothesis has been considered the cornerstone of pathophysiology underlying depression, more recent research provides increasing evidence supporting the role of glutamatergic neurotransmission ${ }^{191}$. One of the proposed hypotheses suggests that disruptions of neuronal synaptic plasticity that leads to glutamatergic signaling dysfunction may ultimately cause depression ${ }^{194}$. Additionally, a prominent reduction of the expression of the NR1 subunit, which is the binding site of D-serine on NMDAr, was demonstrated in several mood disorders including depression ${ }^{195,196}$. NR1 knockout mice exhibited a depression-like phenotype and didn't respond to D-serine treatment ${ }^{194}$. Furthermore, a significant reduction in the number of glial cells, particularly astrocytes, was found in preclinical ${ }^{197}$, clinical, and postmortem ${ }^{198}$ studies on depression. NMDAr antagonists, such as zinc and magnesium, demonstrated anti-depressant activity in depression screening tests ${ }^{199-201}$. The administration of D-serine was found to antagonize the antidepressant effect of both zinc and magnesium in mice ${ }^{202}$, indicating that the NMDAr complex, especially the glycine (B) site, plays a role in the antidepressantlike activity of magnesium and zinc in mice ${ }^{202}$. Although a single, acute D-serine administration produces antidepressantlike effects and supports the idea of complex glutamatergic dysfunction in depression ${ }^{194}$, it is still unclear whether D-serine controls downstream synaptic plasticity cascades that may contribute to its antidepressant-like effects.

Further research is required to specify the exact role of Dserine in the pathophysiology of mood disorders including depression. 


\subsection{Parkinson's Disease}

Parkinson's disease (PD) is one of the most common neurodegenerative diseases of the CNS with extrapyramidal manifestations. Progressive loss of dopaminergic neurons in substantia nigra leads to significant decreases in dopaminergic innervation of basal ganglia and the limbic system ${ }^{203,204}$. The disease has pronounced diversity among patients and that results in differing prognoses of the disease ${ }^{205}$

Since NMDArs are expressed widely in basal ganglia and the limbic system, they were studied for the possible effects of modulation of their function on the improvement of signs and symptoms of PD. It has been found that NMDAr activation enhances dopamine release ${ }^{203}$. Moreover, the depletion of dopamine changes the structure, function, and abundance of NMDArs $^{203}$. On the other hand, glutamate plays an opposing role of dopamine in controlling movement and establishing a delicate balance that results in smooth movement of different body organs ${ }^{206,207}$. Due to depleted dopaminergic innervations in PD, glutamate overstimulation is abundant. Consequently, glutamate antagonists were studied thoroughly as candidates for PD treatment ${ }^{206}$. As a proof of concept, it was confirmed that glutamate inhibition may lead to increased dopaminergic firing, enhance conversion of L-dopa into dopamine, and increase dopamine release from neurons ${ }^{206,208}$. Accordingly, it was anticipated that NMDAr antagonists may be beneficial in the treatment of PD. Surprisingly, clinical studies using agents such as amantadine, dextromethorphan, and dextrorphan on their own resulted in worsening of the symptoms of PD patients ${ }^{206}$. On the other hand, using these agents as adjuvant treatment to L-dopa resulted in improving dyskinesia in PD patients ${ }^{209-213}$.

Currently, multiple lines of evidence suggest that excessive production or release of $\mathrm{D}$-serine might be associated with chronic neurodegeneration. Although the role of D-serine in the pathogenesis of several neurodegenerative diseases has been implicated, the association between D-serine and the development of PD is still unclear and the mechanism is largely ignored. Interestingly, the administration of D-serine as adjuvant treatment to patients with established idiopathic PD resulted in improvement in the disease symptoms, observed by the significant reduction of total scores of various symptom rating scales used for assessing PD patients, such as the Unified Parkinson's Disease Rating Scale (UPDRS), Simpson-Angus Scale for Extrapyramidal Symptoms (SAS), Abnormal Involuntary Movement Scale (AIMS), and Positive and Negative Syndrome Scale (PANSS).

\section{Summary}

D-Serine is now widely recognized to function as an important CNS neuromodulator in health and disease, but its role in pathologic conditions requires further research. Determination of D-serine concentrations in biological fluids and measurement of the activity of its synthesizing and catabolizing enzymes and mutations in their genes might be used to better understand the neurochemical mechanisms of some CNS disorders as well as to identify potential new therapeutic strategies.

\section{ACKNOWLEDGEMENTS}

This publication was supported by funds from the University of Jordan.

\section{REFERENCES}

1. Lamzin VS, Dauter Z, Wilson KS. How nature deals with stereoisomers. Curr Opin Struct Biol. 1995;5:830-6.

2. Mason SF. Origins of biomolecular handedness. Nature. 1984;311: 19-23.

3. Prelog V. Chirality in chemistry. Science. 1976;193:17-24

4. Auclair JL, Patton RL. On the occurrence of D-alanine in the haemolymph of the milkweed bug, oncopeltus fasciatus. Rev Can Biol. 1950;1:3-8.

5. Beatty I, Magrath D, Ennor A. Occurrence of D-serine in lombricine. Nature. 1959;183:591.

6. Corrigan JJ, Srinivasan NG. The occurrence of certain D-amino acids in insects. Biochemistry. 1966;5:1185-90.

7. Kreil G. Peptides containing a D-amino acid from frogs and molluscs. J Biol Chem. 1994;269:10967-70.

8. Preston RL. Occurrence of D-amino acids in higher organisms: a survey of the distribution of D-amino acids in marine vertebrates. Comp Biochem Physiol B. 1987;87:55-62.

9. Dunlop DS, Neidle A, McHale D, Dunlop DM, Lajtha A. The presence of free D-aspartic acid in rodents and man. Biochem Biophys Res Commun. 1986;141:27-32.

10. Hashimoto A, Nishikawa T, Hayashi T, et al. The presence of free D-serine in rat brain. FEBS Lett. 1992;269:33-6.

11. Hashimoto A, Kumashiro S, Nishikawa T, et al. Embryonic development and postnatal changes in free D-aspartate and Dserine in the human prefrontal cortex. J Neurochem. 1993;61: $348-51$.

12. Gustafson EC, Stevens ER, Wolosker H, Miller RF. Endogenous Dserine contributes to NMDA receptor-mediated light-evoked responses in the vertebrate retina. J Neurophysiol. 2007;98: $122-30$

13. Junjaud G, Rouaud E, Turpin F, Mothet JP, Billard JM. Age-related effects of the neuromodulator D-serine on neurotransmission and synaptic potentiation in the CA1 hippocampal area of the rat. J Neurochem. 2006;98:1159-66.

14. Mothet JP, Parent AT, Wolosker H, et al. D-Serine is an endogenous ligand for the glycine site of the N-methyl-D-aspartate receptor. Proc Natl Acad Sci USA. 2000;97:4926-31.

15. Stevens ER, Esguerra M, Kim PM, et al. D-Serine and serine racemase are present in the vertebrate retina and contribute to the physiological activation of NMDA receptors. Proc Natl Acad Sci USA. 2003;100:6789-94.

16. Panatier A, Theodosis DT, Mothet JP, et al. Glia derived D-serine controls NMDA receptor activity and synaptic memory. Cell. 2006;125:775-84.

17. Yang Y, Ge W, Chen Y, et al. Contribution of astrocytes to hippocampal long-term potentiation through release of D-serine. Proc Natl Acad Sci USA. 2003;100:15194-9.

18. Yang S, Qiao H, Wen L, Zhou W, Zhang Y. D-Serine enhances impaired long-term potentiation in CA1 subfield of hippocampal slices from aged senescence-accelerated mouse prone/8. Neurosci Lett. 2005;379:7-12.

19. Kim PM, Aizawa H, Kim PS, et al. Serine racemase: activation by glutamate neurotransmission via glutamate receptor interacting protein and mediation of neuronal migration. Proc Natl Acad Sci USA. 2005; $102: 2105-10$

20. Katsuki H, Nonaka M, Shirakawa H, Kume T, Akaike A. Endogenous D-serine is involved in induction of neuronal death by $\mathrm{N}$-methyl-D-aspartate and simulated ischemia in rat cerebrocortical slices. J Pharmacol Exp Ther. 2004;311:836-44.

21. Kartvelishvily E, Shleper M, Balan L, Dumin E, Wolosker H. Neuron-derived D-serine release provides a novel means to activate N-methyl-D-aspartate receptors. J Biol Chem. 2006; 281:14151-62.

22. Katsuki H, Watanabe Y, Fujimoto S, Kume T, Akaike A. Contribution of endogenous glycine and D-serine to excitotoxic and ischemic cell death in rat cerebrocortical slice cultures. Life Sci. 2007;81:740-9.

23. Sasabe J, Chiba T, Yamada M, et al. D-Serine is a key determinant of glutamate toxicity in amyotrophic lateral sclerosis. EMBO J. 2007;26:4149-59. 
24. Shleper M, Kartvelishvily E, Wolosker H. D-Serine is the dominant endogenous coagonist for NMDA receptor neurotoxicity in organotypic hippocampal slices. J Neurosci. 2005;25:9413-7.

25. Wu SZ, Bodles AM, Porter MM, Griffin WS, Basile AS, Barger $\mathrm{SW}$. Induction of serine racemase expression and D-serine release from microglia by amyloid beta-peptide. J Neuroinflamm. 2004;1:2-13

26. Schell MJ, Molliver ME, Snyder SH. D-Serine, an endogenous synaptic modulator: localization to astrocytes and glutamatestimulated release. Proc Natl Acad Sci USA. 1995;92:3948-52.

27. Puyal J, Martineau M, Mothet JP, Nicolas MT, Raymond J. Changes in D-serine levels and localization during postnatal development of the rat vestibular nuclei. J Comp Neurol. 2006; 497:610-21.

28. Van Horn MR, Sild M, Ruthazer ES. D-Serine as a gliotransmitter and its roles in brain development and disease. Front Cell Neurosci. 2013;7:39-52.

29. De Miranda J, Panizzutti R, Foltyn VN, Wolosker H. Cofactors of serine racemase that physiologically stimulate the synthesis of the N-methyl-D-aspartate (NMDA) receptor coagonist D-serine. Proc Natl Acad Sci USA. 2002;99:14542-7.

30. Wolosker H, Blackshaw S, Snyder SH. Serine racemase: a glial enzyme synthesizing D-serine to regulate glutamate-N-methylD-aspartate neurotransmission. Proc Natl Acad Sci USA. 1999; 96:13409-14.

31. Wolosker H, Sheth KN, Takahashi M, et al. Purification of serine racemase: biosynthesis of the neuromodulator D-serine. Proc Natl Acad Sci USA. 1999;96:721-5.

32. Cook SP, Galve-Roperh I, Martinez Del Pozo A, Rodriguez-Crespo I. Direct calcium binding results in activation of brain serine racemase. J Biol Chem. 2002;277:27782-92.

33. Neidle A, Dunlop DS. Allosteric regulation of mouse brain serine racemase. Neurochem Res. 2002;27:1719-24

34. Strisovsky K, Jiraskova J, Barinka C, et al. Mouse brain serine racemase catalyzes specific elimination of $\mathrm{L}$-serine to pyruvate. FEBS Lett. 2003;535:44-8.

35. Wang LZ, Zhu XZ. Spatiotemporal relationships among D-serine, serine racemase, and $\mathrm{D}$-amino acid oxidase during mouse postnatal development. Acta Pharmacol Sin. 2003;24:965-74.

36. De Miranda J, Santoro A, Engelender S, Wolosker H. Human serine racemase: molecular cloning, genomic organization and functional analysis. Gene. 2000;256:183-8.

37. Basu AC, Tsai GE, Hani L, et al. Abnormal sensory gating, reversal of spatial memory, and anxiety-like behavior in serine racemase knockout mice. Soc Neurosci Abstr. 2007;275:3514-26.

38. Ma CL, Tsai GE, Coyle JT, Basu AC, Bergeron R. Serine racemase null mutant mice show disrupted NMDA receptor function at the hippocampal schaffer collateral-CA1 pyramidal cell synapse. Soc Neurosci Abstr. 2007;576.

39. Mustafa AK, Ehmsen JT, Zeynalov E, et al. D-Serine deficient mice display NMDA receptor dysfunction and reduced stroke damage. Soc Neurosci Abstr. 2007;576.

40. Zhao YL, Takata Y, Hashimoto K, Sakimura K, Mori H. Study of $\mathrm{D}$-serine function in vivo by establishing and analysis of serine racemase knockout mouse. Neurosci Res. 2007;58:346-52.

41. Benneyworth MA, Li Y, Basu AC, Bolshakov VY, Coyle JT. Cell selective conditional null mutations of serine racemase demonstrate a predominate localization in cortical glutamatergic neurons. Cell Mol Neurobiol. 2012;32:613-24.

42. Foltyn VN, Bendikov I, De Miranda J, et al. Serine racemase modulates intracellular D-serine levels through an alpha,betaelimination activity. J Biol Chem. 2005;3:1754-63.

43. Furuya S, Tabata T, Mitoma J, et al. L-Serine and glycine serve as major astroglia-derived trophic factors for cerebellar Purkinje neurons. Proc Natl Acad Sci USA. 2000;97:11528-33

44. Yamasaki M, Yamada K, Furuya S, Mitoma J, Hirabayashi Y, Watanabe M. 3-Phosphoglycerate dehydrogenase, a key enzyme for L-serine biosynthesis, is preferentially expressed in the radial glia/astrocyte lineage and olfactory ensheathing glia in the mouse brain. J Neurosci. 2001;21:7691-704.

45. Wolosker H. Serine racemase and the serine shuttle between neurons and astrocytes. Biochim Biophys Acta. 2011;1814: $1558-66$.
46. Krebs HA. Metabolism of amino acids. III. Determination of amino acids. Biochem J. 1935;29:1620-44.

47. Pollegioni L, Harris CM, Molla G, Pilone MS, Ghisla S. Identification and role of ionizing functional groups at the active center of Rhodotorula gracilis D-amino acid oxidase. FEBS Lett. 2001;507:323-6.

48. Hashimoto A, Nishikawa T, Konno R, et al. Free D-serine, Daspartate and D-alanine in central nervous system and serum in mutant mice lacking D-amino acid oxidase. Neurosci Lett. 1993; 152:33-6.

49. Morikawa A, Hamase K, Inoue T, Konno R, Niwa A, Zaitsu K. Determination of free $\mathrm{D}$-aspartic acid, $\mathrm{D}$-serine and $\mathrm{D}$-alanine in the brain of mutant mice lacking D-amino acid oxidase activity. J Chromatogr B Biomed Sci Appl. 2001;757:119-25.

50. D'Aniello A, Vetere A, Petrucelli L. Further study on the specificity of D-amino acid oxidase and D-aspartate oxidase and time course for complete oxidation of D-amino acids. Comp Biochem Physiol B. 1993;105:731-4.

51. Nagata Y, Konno R, Yasumura Y, Akino T. Involvement of D-amino acid oxidase in elimination of free $\mathrm{D}$-amino acids in mice. Biochem J. 1989;257:291-2.

52. Urai Y, Jinnouchi O, Kwak KT, Suzue A, Nagahiro S, Fukui K. Gene expression of D-amino acid oxidase in cultured rat astrocytes: regional and cell type specific expression. Neurosci Lett. 2002;324:101-4

53. Danysz W, Parsons CG. Glycine and N-methyl-D-aspartate receptors: physiological significance and possible therapeutic applications. Pharmacol Rev. 1998;4:597-664.

54. Paoletti P, Neyton J. NMDA receptor subunits: function and pharmacology. Curr Opin Pharmacol. 2007;7:39-47.

55. McBain CJ, Kleckner NW, Wyrick S, Dingledine R. Structural requirements for activation of the glycine coagonist site of $\mathrm{N}$ methyl-D-aspartate receptors expressed in Xenopus oocytes. Mol Pharmacol. 1989;36:556-65.

56. Fadda E, Danysz W, Wroblewski JT, Costa E. Glycine and D-serine increase the affinity of N-methyl-D-aspartate sensitive glutamate binding sites in rat brain synaptic membranes. Neuropharmacology. 1988;27:1183-5.

57. Lerma J, Zukin RS, Bennett MV. Glycine decreases desensitization of N-methyl-D-aspartate (NMDA) receptors expressed in Xenopus oocytes and is required for NMDA responses. Proc Natl Acad Sci USA. 1990;87:2354-8.

58. Nong Y, Huang YQ, Ju W, et al. Glycine binding primes NMDA receptor internalization. Nature. 2003;422:302-7.

59. Furukawa H, Gouaux E. Mechanisms of activation, inhibition and specificity: crystal structures of the NMDA receptor NR1 ligand-binding core. EMBO J. 2003;22:2873-85.

60. Constantine-Paton M, Cline HT, Debski E. Patterned activity, synaptic convergence, and the NMDA receptor in developing visual pathways. Annu Rev Neurosci. 1990;13:129-54.

61. Henneberger C, Papouin T, Oliet SH, Rusakov DA. Long-term potentiation depends on release of $\mathrm{D}$-serine from astrocytes. Nature. 2010;463:232-6.

62. Stevens ER, Gustafson EC, Sullivan SJ, Esguerra M, Miller RF. Light-evoked NMDA receptor-mediated currents are reduced by blocking D-serine synthesis in the salamander retina. Neuroreport. 2010;21:239-44

63. Fossat P, Turpin FR, Sacchi S, et al. Glial D-serine gates NMDA receptors at excitatory synapses in prefrontal cortex. Cereb Cortex. 2012;22:595-606.

64. Kaufman AM, Milnerwood AJ, Sepers MD, et al. Opposing roles of synaptic and extrasynaptic NMDA receptor signaling in cocultured striatal and cortical neurons. J Neurosci. 2012;32: 3992-4003.

65. Papouin T, Ladépêche L, Ruel J, et al. Synaptic and extrasynaptic NMDA receptors are gated by different endogenous coagonists. Cell. 2012;150:633-46.

66. Mothet JP, Rouaud E, Sinet PM, et al. A critical role for the glialderived neuromodulator D-serine in the age-related deficits of cellular mechanisms of learning and memory. Aging Cell. 2006; 5:267-74. 
67. Berger AJ, Dieudonne S, Ascher P. Glycine uptake governs glycine site occupancy at NMDA receptors of excitatory synapses. J Neurophysiol. 1998;80:3336-40.

68. Bergeron R, Meyer TM, Coyle JT, Greene RW. Modulation of Nmethyl-D-aspartate receptor function by glycine transport. Proc Natl Acad Sci USA. 1998;95:15730-4.

69. Sakata Y, Owada Y, Sato K, et al. Structure and expression of the glycine cleavage system in rat central nervous system. Brain Res Mol Brain Res. 2001;94:119-30.

70. Sato K, Yoshida S, Fujiwara K, Tada K, Tohyama M. Glycine cleavage system in astrocytes. Brain Res. 1991;567:64-70.

71. Zafra F, Aragon C, Gimenez C. Molecular biology of glycinergic neurotransmission. Mol Neurobiol. 1997;14:117-42.

72. Ribeiro CS, Reis M, Panizzutti R, de Miranda J, Wolosker H. Glial transport of the neuromodulator D-serine. Brain Res. 2002;929: 202-9.

73. Fukasawa Y, Segawa H, Kim JY, et al. Identification and characterization of a $\mathrm{Na}(+)$-independent neutral amino acid transporter that associates with the 4F2 heavy chain and exhibits substrate selectivity for small neutral D- and L-amino acids. J Biol Chem. 2000;275:9690-8.

74. Helboe L, Egebjerg J, Moller M, Thomsen C. Distribution and pharmacology of alanine-serine-cysteine transporter 1 (asc-1) in rodent brain. Eur J Neurosci. 2003;18:2227-38.

75. Matsuo H, Kanai Y, Tokunaga M, et al. High affinity D- and Lserine transporter Asc-1: cloning and dendritic localization in the rat cerebral and cerebellar cortices. Neurosci Lett. 2004;358: $123-6$.

76. Nakauchi J, Matsuo H, Kim DK, et al. Cloning and characterization of a human brain $\mathrm{Na}(+)$-independent transporter for small neutral amino acids that transports D-serine with high affinity. Neurosci Lett. 2000;287:231-5.

77. Hayashi F, Takahashi K, Nishikawa T. Uptake of D- and L-serine in C6 glioma cells. Neurosci Lett. 1997;239:85-8.

78. Rutter AR, Fradley RL, Garrett EM, et al. Evidence from gene knockout studies implicates Asc-1 as the primary transporter mediating D-serine reuptake in the mouse CNS. Eur J Neurosci. 2007;25:1757-66.

79. Shao Z, Kamboj A, Anderson CM. Functional and immunocytochemical characterization of D-serine transporters in cortical neuron and astrocyte cultures. J Neurosci Res. 2009;87:2520-30.

80. Horiike K, Tojo H, Arai R, Nozaki M, Maeda T. D-Amino-acid oxidase is confined to the lower brain stem and cerebellum in rat brain: regional differentiation of astrocytes. Brain Res. 1994; 652:297-303

81. Hashimoto A. Effect of the intracerebroventricular and systemic administration of L-serine on the concentrations of D- and Lserine in several brain areas and periphery of rat. Brain Res. 2002;955:214-20.

82. Boehning D, Snyder SH. Novel neural modulators. Annu Rev Neurosci. 2003;26:105-31.

83. Hashimoto A, Oka T, Nishikawa T. Anatomical distribution and postnatal changes in endogenous free $\mathrm{D}$-aspartate and $\mathrm{D}$-serine in rat brain and periphery. Eur J Neurosci. 1995;7:1657-63.

84. Chahal H, D'Souza SW, Barson AJ, Slater P. Modulation by magnesium of $\mathrm{N}$-methyl-D-aspartate receptors in developing human brain. Arch Dis Child Fetal Neonatal Ed. 1998;78: F116-20.

85. Panigrahy A, Rosenberg PA, Assmann S, Foley EC, Kinney HC. Differential expression of glutamate receptor subtypes in human brainstem sites involved in perinatal hypoxia-ischemia. J Comp Neurol. 2000;427:196-208.

86. Piggott MA, Perry EK, Perry RH, Court JA. [3H]MK-801 binding to the NMDA receptor complex, and its modulation in human frontal cortex during development and aging. Brain Res. 1992; 588:277-86.

87. Slater P, McConnell SE, D'Souza SW, Barson AJ. Postnatal changes in N-methyl-D-aspartate receptor binding and stimulation by glutamate and glycine of [3H]-MK-801 binding in human temporal cortex. Br J Pharmacol. 1993;108:1143-9.

88. Crair MC, Malenka RC. A critical period for long-term potentiation at thalamocortical synapses. Nature. 1995;375:325-8.
89. Feldman DE, Nicoll RA, Malenka RC, Isaac JT. Long-term depression at thalamocortical synapses in developing rat somatosensory cortex. Neuron. 1998;21:347-57.

90. Ramoa AS, McCormick DA. Enhanced activation of NMDA receptor responses at the immature retinogeniculate synapse. J Neurosci. 1994;14:2098-105.

91. Fuchs SA, Dorland L, de Sain-van der Velden MG, et al. D-Serine in the developing human central nervous system. Ann Neurol. 2006;60:476-80.

92. Komuro H, Rakic P. Modulation of neuronal migration by NMDA receptors. Science. 1993;260:95-7.

93. Hepner F, Pollak A, Ulfig N, Yae-Kyung M, Lubec G. Mass spectrometrical analysis of human serine racemase in foetal brain. J Neural Transm. 2005;112:805-11.

94. Adesnik H, Li G, During MJ, Pleasure SJ, Nicoll RA. NMDA receptors inhibit synapse unsilencing during brain development. Proc Natl Acad Sci USA. 2008;105:5597-602.

95. Rabacchi S, Bailly Y, Delhaye-Bouchaud N, Mariani J. Involvement of the N-methyl-D-aspartate (NMDA) receptor in synapse elimination during cerebellar development. Science. 1992;256:1823-5.

96. Bliss TV, Collingridge GL. A synaptic model of memory: long-term potentiation in the hippocampus. Nature. 1993;361:31-9.

97. Basu AC, Tsai GE, Ma CL, et al. Targeted disruption of serine racemase affects glutamatergic neurotransmission and behavior. Mol Psychiatry. 2009;14:719-27.

98. Almond SL, Fradley RL, Armstrong EJ, et al. Behavioral and biochemical characterization of a mutant mouse strain lacking D-amino acid oxidase activity and its implications for schizophreni. Mol Cell Neurosci. 2006;32:324-34.

99. Maekawa M, Watanabe M, Yamaguchi S, Konno R, Hori Y. Spatial learning and long-term potentiation of mutant mice lacking Damino-acid oxidase. Neurosci Res. 2005;53:34-8.

100.Turpin FR, Potier B, Dulong JR, et al. Reduced serine racemase expression contributes to age-related deficits in hippocampal cognitive function. Neurobiol Aging. 2009;8:1495-504.

101. Choi DW, Rothman SM. The role of glutamate neurotoxicity in hypoxic-ischemic neuronal death. Annu Rev Neurosci. 1990;13: 171-82.

102. Inoue R, Hashimoto K, Harai T, Mori H. NMDA- and betaamyloid1-42-induced neurotoxicity is attenuated in serine racemase knock-out mice. J Neurosci. 2008;28:14486-91.

103. Paul P, de Belleroche J. The role of D-amino acids in amyotrophic lateral sclerosis pathogenesis: a review. Amino Acids. 2012;43: $1823-31$.

104. Bruijn LI, Miller TM, Cleveland DW. Unraveling the mechanisms involved in motor neurondegeneration in ALS. Annu Rev Neurosci. 2004;27:723-49.

105. Rothstein JD, Tsai G, Kuncl RW, et al. Abnormal excitatory amino acid metabolism in amyotrophic lateral sclerosis. Ann Neurol. 1990;28:18-25.

106. Mitchell J Paul P, Chen HJ, et al. Familial amyotrophic lateral sclerosis is associated with a mutation in D-amino acid oxidase. Proc Natl Acad Sci USA. 2010;107:7556-61.

107. Olney JW, Wozniak DF, Farber NB. Excitotoxic neurodegeneration in Alzheimer disease. New hypothesis and new therapeutic strategies. Arch Neurol. 1997;54:1234- 40.

108. Kornhuber J, Weller M. Psychotogenicity and N-methyl-Daspartate receptor antagonism: implications for neurodegenerative pharmacotherapy. Biol Psychiatry. 1997;41: 135-44.

109. Newcomer JW, Krystal JH. NMDA receptor regulation of memory and behavior in humans. Hippocampus. 2001;11:529-42.

110. Loftis JM, Janowsky A. The N-methyl-D-aspartate receptor subunit NR2B: localization, functional properties, regulation, and clinical implications. Pharmacol Ther. 2003;97:55-85.

111. Maragos WF, Chu DC, Young AB, D'Amato CJ, Penney Jr JB. Loss of hippocampal [3H]TCP binding in Alzheimer's disease. Neurosci Lett. 1987;74:371-6.

112. Procter AW, Wong EH, Stratmann GC, Lowe SL, Bowen DM. Reduced glycine stimulation of $[3 \mathrm{H}] \mathrm{MK}-801$ binding in Alzheimer's disease. J Neurochem. 1989;53:698-704. 
113. Sze C, Bi H, Kleinschmidt-DeMasters BK, Filley CM, Martin LJ. N-Methyl-D-aspartate receptor subunit proteins and their phosphorylation status are altered selectively in Alzheimer's disease. J Neurol Sci. 2001;182:151-9.

114. Reisberg B, Doody R, Stoffler A, Schmitt F, Ferris S, Mobius HJ. Memantine Study Group. Memantine in moderate-to-severe Alzheimer's disease. N Engl J Med. 2003;348:1333-41.

115. Suh YH, Checler F. Amyloid precursor protein, presenilins, and alpha-synuclein: molecular pathogenesis and pharmacological applications in Alzheimer's disease. Pharmacol Rev. 2002;54: 469-525.

116. Brito-Moreira J, Paula-Lima AC, Bomfim TR, et al. Abeta oligomers induce glutamate release from hippocampal neurons. Curr Alzheimer Res. 2011;5:552-62.

117. Wu S, Basile AS, Barger SW. Induction of serine racemase expression and D-serine release from microglia by secreted amyloid precursor protein (sAPP). Curr Alzheimer Res. 2007;4: 243-51

118. Peterson SL. Anticonvulsant drug potentiation by glycine in maximal electroshock seizures is mimicked by D-serine and antagonized by 7-chlorokynurenic acid. Eur J Pharmacol. 1991; 199:341-8.

119. Loscher W, Wlaz P, Rundfeldt C, Baran H, Honack D. Anticonvulsant effects of the glycine/NMDA receptor ligands Dcycloserine and D-serine but not R-(+)-HA-966 in amygdalakindled rats. Br J Pharmacol. 1994;112:97-106.

120. Schwartz BL, Hashtroudi S, Herting RL, Schwartz P, Deutsch SI. D-Cycloserine enhances implicit memory in Alzheimer patients. Neurology. 1996;46:420-4.

121. Tsai G, Falk WE, Gunther J, Coyle JT. Improved cognition in Alzheimer's disease with short-term D-cycloserine treatment. Am J Psychiatr. 1999; 156:467-9.

122. Andersen JM, Fonnum F, Myhrer T. D-Serine alleviates retrograde amnesia of a visual discrimination task in rats with a lesion of the perirhinal cortex. Brain Res. 2003;979:240-4.

123. Singh L, Oles RJ, Tricklebank MD. Modulation of seizure susceptibility in the mouse by the strychnine-insensitive glycine recognition site of the NMDA receptor/ion channel complex. $\mathrm{Br}$ J Pharmacol. 1990;99:285-8.

124.De SG, Trimarchi GR, Sinopoli S, Masuda Y, De SA. Anticonvulsant effects of U-54494A and U-50488 $\mathrm{H}$ in genetically epilepsy-prone rats and DBA/2 mice: a possible involvement of glycine/NMDA receptor complex. Gen Pharmacol. 1993;24:439-47.

125. Peterson SL. Infusion of NMDA antagonists into the nucleus reticularis pontis oralis inhibits the maximal electroshock seizure response. Brain Res. 1995;702:101-10.

126.Liu YH, Wang L, Wei LC, Huang YG, Chen LW. Up-regulation of $\mathrm{D}$-serine might induce GABAergic neuronal degeneration in the cerebral cortex and hippocampus in the mouse pilocarpine model of epilepsy. Neurochem Res. 2009;34:1209-18.

127. Rossetti AO, Logroscino G, Liaudet L, et al. Status epilepticus: an independent outcome predictor after cerebral anoxia. Neurology. 2007;69:255-60.

128. Ryu HJ, Kim JE, Yeo SI, et al. Potential roles of D-serine and serine racemase in experimental temporal lobe epilepsy. J Neurosci Res. 2010;88:2469-82.

129. Robinson JL, Monkul ES, Tordesillas-Gutiérrez D, et al. Frontolimbic circuitry in euthymic bipolar disorder: evidence for prefrontal hyperactivation. Psychiatry Res. 2008;164:106-13.

130.American Psychatric Association. Diagnostic and Statistical Manual of Mental Disorders: DSM-IV. 4th ed. Washington, DC. American Psychiatric Association 1994:866 p.

131. Chen YS, Akula N, Detera-Wadleigh SD, et al. Findings in an independent sample support an association between bipolar affective disorder and the G72/G30 locus on chromosome 13q33. Mol Psychiatry. 2004;9:87-92.

132. Hattori E, Liu C, Badner JA, et al. Polymorphisms at the G72/G30 gene locus, on $13 \mathrm{q} 33$, are associated with bipolar disorder in two independent pedigree series. Am J Hum Genet. 2003;72: 1131-40.
133. Muller DJ, Zai CC, Shinkai T, Strauss J, Kennedy JL. Association between the DAOA/G72 gene and bipolar disorder and metaanalyses in bipolar disorder and schizophrenia. Bipolar Disord. 2011;13:198-207.

134. Prata D, Breen G, Osborne S, Munro J, St Clair D, Collier D. Association of DAO and G72(DAOA)/G30 genes with bipolar affective disorder. Am J Med Genet B Neuropsychiatr Genet. 2008;147B:914-7.

135. Schumacher J, Jamra RA, Freudenberg J, et al. Examination of G72 and D-amino-acid oxidase as genetic risk factors for schizophrenia and bipolar affective disorder. Mol Psychiatry. 2004;9:203-7.

136. Williams NM, Green EK, Macgregor S, et al. Variation at the DAOA/G30 locus influences susceptibility to major mood episodes but not psychosis in schizophrenia and bipolar disorder. Arch Gen Psychiatry. 2006;63:366-73.

137.Zhang Z, Li Y, Zhao Q, et al. First evidence of association between G72 and bipolar disorder in the Chinese Han population. Psychiatr Genet. 2009;19:151-3.

138. Abou JR, Gobina CM, Becker T, et al. Association study between genetic variants at the VAMP2 and VAMP3 loci and bipolar affective disorder. Psychiatr Genet. 2008;18:199-203.

139. Hashimoto K, Sawa A, Iyo M. Increased levels of glutamate in brains from patients with mood disorders. Biol Psychiatry. 2007; 62:1310-6.

140. Robertson CM, Finer NN, Grace MG. School performance of survivors of neonatal encephalopathy associated with birth asphyxia at term. J Pediatr. 1989;114:753-60.

141. Shankaran S, Woldt E, Koepke T, Bedard MP, Nandyal R. Acute neonatal morbidity and long-term central nervous system sequelae of perinatal asphyxia in term infants. Early Hum Dev. 1991;25:135-48.

142. Sattler R, Tymianski M. Molecular mechanisms of glutamate receptor-mediated excitotoxic neuronal cell death. Mol Neurobiol. 2001;24:107-29.

143. Mustafa AK, Ahmad AS, Zeynalov E, et al. Serine racemase deletion protects against cerebral ischemia and excitotoxicity. J Neurosci. 2010;30:1413-6.

144.Goff DC, Coyle JT. The emerging role of glutamate in the pathophysiology and treatment of schizophrenia. Am J Psychiatr. 2001;158:1367-77.

145. Murray CJL, Lopez AD, Harvard School of Public Health; World Health Organization, World Bank. The Global Burden of Disease: a Comprehensive Assessment of Mortality and Disability from Diseases, Injuries, and Risk Factors in 1990 and Projected to 2020. Published by the Harvard School of Public Health on behalf of the World Health Organization and the World Bank; Distributed by Harvard University Press, Cambridge, MA 1996; vol xxxii.

146. Lisman JE, Coyle JT, Green RW, et al. Circuit-based framework for understanding neurotransmitter and riskgene interactions in schizophrenia. Trends Neurosci. 2008;31:234-42.

147. Janowsky DS, Risch C. Amphetamine psychosis and psychotic symptoms. Psychopharmacology. 1979;65:73-7.

148. Seeman P, Chau-Wong M, Tedesco J, Wong K. Brain receptors for antipsychotic drugs and dopamine: direct binding assays. Proc Natl Acad Sci U S A. 1975;72:4376-80.

149. Creese I, Burt DR, Snyder SH. Dopamine receptor binding predicts clinical and pharmacological potencies of antischizophrenic drugs. Science. 1976;192:481-3.

150. Tsai G, Yang P, Chung LC, Lange N, Coyle JT. D-Serine added to antipsychotics for the treatment of schizophrenia. Biol Psychiatry. 1998;44:1081-9.

151. Lewis DA, Moghaddam B. Cognitive dysfunction in schizophrenia: convergence of gamma-aminobutyric acid and glutamate alterations. Arch Neurol. 2006;63:1372-6.

152. Javitt DC, Zukin SR. Recent advances in the phencyclidine model of schizophrenia. Am J Psychiatry. 1991;148:1301-8.

153. Krystal JH, Karper LP, Seibyl JP, et al. Subanesthetic effects of the noncompetitive NMDA antagonist, ketamine, in humans. Psychotomimetic, perceptual, cognitive, and neuroendocrine responses. Arch Gen Psychiatry. 1994;51:199-214. 
154. Yee BK, Chang DT, Feldon J. The effects of dizocilpine and phencyclidine on prepulse inhibition of the acoustic startle reflex and on prepulse-elicited reactivity in C57BL6 mice. Neuropsychopharmacology. 2004;29:1865-77.

155. Lipina T, Labrie V, Weiner I, Roder J. Modulators of the glycine site onNMDA receptors, D-serine and ALX 5407, display similar beneficial effects to clozapine in mouse models of schizophrenia. psychopharmacology (Berl). 2005;179:54-67.

156. Mandillo S, Rinaldi A, Oliverio A, Mele A. Repeated administration of phencyclidine, amphetamine and MK-801 selectively impairs spatial learning in mice: a possible model of psychotomimetic drug-induced cognitive deficits. Behav Pharmacol. 2003;14:533-44.

157.Linn GS, Negi SS, Gerum SV, Javitt DC. Reversal of phencyclidineinduced prepulse inhibition deficits by clozapine in monkeys. Psychopharmacology. 2003;169:243-9.

158. Mao CV, Hori E, Maior RS, Ono T, Nishijo H. A primate model of schizophrenia using chronic PCP treatment. Rev Neurosci. 2008; 19:83-9.

159. Thompson DM, Winsauer PJ, Mastropaolo J. Effects of phencyclidine, ketamine and MDMA on complex operant behavior in monkeys. Pharmacol Biochem Behav. 1987;26: 401-5.

160. Bubeníková-Valesová V, Horácek J, Vrajová M, Höschl C. Models of schizophrenia in humans and animals based on inhibition of NMDA receptors. Neurosci Biobehav Rev. 2008;32:1014-23.

161. Bendikov I, Nadri C, Amar S, et al. A CSF and postmortem brain study of D-serine metabolic parameters in schizophrenia. Schizophr Res. 2007;90:41-51.

162. Hashimoto K, Engberg G, Shimizu E, Nordin C, Lindstrom LH, Iyo M. Reduced D-serine to total serine ratio in the cerebrospinal fluid of drug naive schizophrenic patients. Prog Neuropsychopharmacol Biol Psychiatry. 2005;29:767-9.

163. Hashimoto K, Fukushima T, Shimizu E, et al. Decreased serum levels of D-serine in patients with schizophrenia: evidence in support of the N-methyl-D-aspartate receptor hypofunction hypothesis of schizophrenia. Arch Gen Psychiatry. 2003;60: 572-6.

164. Calcia MA, Madeira C, Alheira FV, et al. Plasma levels of D-serine in Brazilian individuals with schizophrenia. Schizophr Res. 2012;142:83-7.

165. Kumashiro S, Hashimoto A, Nishikawa T. Free D-serine in postmortem brains and spinal cords of individuals with and without neuropsychiatric diseases. Brain Res. 1995;681:117-25.

166. Madeira C, Freitas ME, Vargas-Lopes C, Wolosker H, Panizzutti R. Increased brain D-amino acid oxidase (DAAO) activity in schizophrenia. Schizophr Res. 2008;101:76-83.

167. Habl G, Zink M, Petroianu G, et al. Increased D-amino acid oxidase expression in the bilateral hippocampal CA4 of schizophrenic patients: a post-mortem study. J Neural Transm. 2009;116: 1657-65.

168. Allen NC, Bagade S, McQueen MB, et al. Systematic metaanalyses and field synopsis of genetic association studies in schizophrenia: the SzGene database. Nat Genet. 2008;40: 827-34.

169. Shi J, Gershon ES, Liu C. Genetic associations with schizophrenia: meta-analyses of 12 candidate genes. Schizophr Res. 2008;10: 96-107.

170. Sun J, Kuo PH, Riley BP, Kendler KS, Zhao Z. Candidate genes for schizophrenia: a survey of association studies and gene ranking. Am J Med Genet B Neuropsychiatr Genet. 2008;147B:1173-81.

171. Burnet PW, Eastwood SL, Bristow GC, et al. D-Amino acid oxidase activity and expression are increased in schizophrenia. Mol Psychiatry. 2008;13:658-60.

172. Kapoor R, Lim KS, Cheng A, Garrick T, Kapoor V. Preliminary evidence for a link between schizophrenia and NMDA-glycine site receptor ligand metabolic enzymes, D-amino acid oxidase (DAAO) and kynurenine amino transferase-1 (KAT-1). Brain Res. 2006;1106:205-10.

173. Verrall L, Walker M, Rawlings N, et al. D-Amino acid oxidase and serine racemase in human brain: normal distribution and altered expression in schizophrenia. Eur J Neurosci. 2007;26:1657-69.
174. Morita Y, Ujike H, Tanaka Y, et al. A genetic variant of the serine racemase gene is associated with schizophrenia. Biol Psychiatry. 2007;61:1200-3.

175.Labrie V, Fukumura R, Rastogi A, et al. Serine racemase is associated with schizophrenia susceptibility in humans and in a mouse model. Hum Mol Genet. 2009;18:3227-43.

176. Boks MP, Rietkerk T, van de Beek MH, Sommer IE, de Koning TJ, Kahn RS. Reviewing the role of the genes G72 and DAAO in glutamate neurotransmission in schizophrenia. Eur Neuropsychopharmacol. 2007;17:567-72.

177. Caldinelli L, Sacchi S, Molla G, Nardini M, Pollegioni L. Characterization of human DAAO variants potentially related to an increased risk of schizophrenia. Biochim Biophys Acta. 2013;1832:400-10.

178. Chumakov I, Blumenfeld M, Guerassimenko O, et al. Genetic and physiological data implicating the new human gene G72 and the gene for D-amino acid oxidase in schizophrenia. Proc Natl Acad Sci U S A. 2002;99:13675-80.

179.Detera-Wadleigh SD, McMahon FJ. G72/G30 in schizophrenia and bipolar disorder: review and meta-analysis. Biol Psychiatry. 2006;60:106-14

180.Goldberg TE, Straub RE, Callicott JH, et al. The G72/G30 gene complex and cognitive abnormalities in schizophrenia. Neuropsychopharmacol. 2006;31:2022-32.

181. Korostishevsky M, Kaganovich M, Cholostoy A, et al. Is the G72/G30 locus associated with schizophrenia? Single nucleotide polymorphisms, haplotypes, and gene expression analysis. Biol Psychiatry. 2004;56:169-76.

182. Korostishevsky M, Kremer I, Kaganovich M, et al. Transmission disequilibrium and haplotype analyses of the G72/G30 locus: suggestive linkage to schizophrenia in Palestinian Arabs living in the North of Israel. Am J Med Genet B Neuropsychiatr Genet. 2006;141B:91-5.

183. Wang X, He G, Gu N, et al. Association of G72/G30 with schizophrenia in the Chinese population. Biochem Biophys Res Commun. 2004;319:1281-6.

184.Zou F, Li C, Duan S, et al. A family-based study of the association between the G72/G30 genes and schizophrenia in the Chinese population. Schizophr Res. 2005;73:257-61.

185. Otte DM, Bilkei-Gorzó A, Filiou MD,et al. Behavioral changes in G72/G30 transgenic mice. Eur Neuropsychopharmacol. 2009;5: $339-48$.

186. Heresco-Levy U, Javitt DC, Ebstein R, et al. D-Serine efficacy as add-on pharmacotherapy to risperi-done and olanzapine for treatment- refractory schizophrenia. Biol Psychiatry. 2005;57: $577-85$.

187. Kantrowitz JT, Malhotra AK, Cornblatt B, et al. High dose D-serine in the treatment of schizophrenia. Schizophr Res. 2010;121: 125-30.

188. D'Souza DC, Radhakrishnan R, Perry E, et al. Feasibility, safety, and efficacy of the combination of D-serine and computerized cognitive retraining in schizophrenia: an international collaborative pilot study. Neuropsychopharmacol. 2013;38: 492-503.

189. Belmaker RH, Agam G. Major depressive disorder. New Engl J Med. 2008;358:55-68.

190. Van Praag H. Monoamine precursors in depression: present state and prospects. In: Zohar J, Belmaker RH, editors. Treating resistant depression. New York: PMA Publishing 1987:279-306

191. Choudary PV, Molnar M, Evans SJ, et al. Altered cortical glutamatergic and GABAergic signal transmission with glial involvement in depression. Proc Natl Acad Sci USA. 2005;102: 15653-8.

192. Lewy AJ, Lefler BJ, Emens JS, Bauer VK. The circadian basis of winter depression. Proc Natl Acad Sci USA. 2006;103:7414-9.

193. Duman RS. Neuronal damage and protection in the pathophysiology and treatment of psychiatric illness: stress and depression. Dialogues Clin Neurosci. 2009;11:239-55.

194. Malkesman O, Austin DR, Tragon T, et al. Acute D-serine treatment produces antidepressant-like effects in rodents. Int $\mathrm{J}$ Neuropsychopharmacol. 2012;8:1135-48.

195. McCullumsmith RE, Kristiansen LV, Beneyto M, Scarr E, Dean B, Meador-Woodruff JH. Decreased NR1, NR2A, and SAP102 
transcript expression in the hippocampus in bipolar disorder. Brain Res. 2007;1127:108-18.

196. Nudmamud-Thanoi S, Reynolds GP. The NR1 subunit of the glutamate/NMDA receptor in the superior temporal cortex in schizophrenia and affective disorders. Neurosci Lett. 2004;372: 173-7.

197. Banasr M, Chowdhury GM, Terwilliger R, et al. Glial pathology in an animal model of depression: reversal of stress-induced cellular, metabolic and behavioral deficits by the glutamatemodulating drug riluzole. Mol Psychiatry. 2010;15:501-11.

198. Cotter D, Mackay D, Landau S, Kerwin R, Everall I. Reduced glial cell density and neuronal size in the anterior cingulate cortex in major depressive disorder. Arch Gen Psychiatry. 2001;58: 545-53.

199. Eby GA, Eby KL. Rapid recovery from major depression using magnesium treatment. Med Hypotheses. 2006;67:362-70.

200. Kroczka B, Brañski P, Palucha A, Pilc A, Nowak G. Antidepressantlike properties of zinc in rodent forced swim test. Brain Res Bull. 2001;55:297-300.

201.Kroczka B, Ziêba A, Dudek D, Pilc A, Nowak G. Zinc exhibits an antidepressant-like effect in the forced swimming test in mice. Pol J Pharmacol. 2000;52:403-6.

202.Poleszak E, Szewczyk B, Wlaź A, et al. D-Serine, a selective glycine/N-methyl-D-aspartate receptor agonist, antagonizes the antidepressant-like effects of magnesium and zinc in mice. Pharmacol Rep. 2008;60:996-1000.

203. Gelfin E, Kaufman Y, Korn-Lubetzki I, et al. D-Serine adjuvant treatment alleviates behavioural and motor symptoms in Parkinson's disease. Int J Neuropsychopharmacol. 2012;4: 543-9.

204. Braak H, Braak E. Pathoanatomy of Parkinson's disease. J Neurol Sci. 2000;247:3-10.
205. Hoehn MM, Yahr MD. Parkinsonism: onset, progression and mortality. Neurology. 1967;17:427-42.

206. Starr MS. Antagonists of glutamate in the treatment of Parkinson's disease: from laboratory to the clinic. Amino Acids. 1998;14: 41-2.

207. Hallett PJ, Standaert DG. Rationale for and use of NMDA antagonists in Parkinson's disease. Pharmacolo Ther. 2004;10: 155-74.

208. Johnson KA, Conn PJ, Niswender CM. Glutamate receptors as therapeutic targets for Parkinson's disease. CNS Neurol Disord Drug Targets. 2009 Dec;8(6):475-91 .

209. Crosby NJ, Deane KH, Clarke CE. Amantadine for dyskinesia in Parkinson's disease. Cochrane Database Syst Rev. 2003;2: 3467-81.

210.Del Dotto P, Pavese N, Gambaccini G, et al. Intravenous amantadine improves levadopa-induced dyskinesias: an acute double-blind placebo-controlled study. Mov Disord. 2001;3: 515-20.

211. Verhagen Metman L, Blanchet PJ, van den Munckhof P, Del Dotto P, Natté R, Chase TN. A trial of dextromethorphan in parkinsonian patients with motor response complications. Mov Disord. 1998:3:414-7.

212. Verhagen Metman L, Del Dotto P, van den Munckhof P, Fang J, Mouradian MM, Chase TN. Amantadine as treatment for dyskinesias and motor fluctuations in Parkinson's disease. Neurology. 1998;5:1323-6.

213. Blanchet PJ, Metman LV, Mouradian MM, Chase TN. Acute pharmacologic blockade of dyskinesias in Parkinson's disease. Mov Disord. 1996;5:580-1. 